\title{
Algunas consideraciones respecto de cláusulas típicas en contratos de M\&A a la luz de las normas civiles peruanas
}

Daniel Gonzáles La Rosa

Abogado por la Pontificia Universidad Católica del Perú. Máster en Derecho (LL.M.) por the University of Chicago.

SUMARI0:

I. Introducción.

II. Limitaciones temporales para interponer reclamos bajo Contratos de Compraventa de Acciones.

1. Normas civiles de Prescripción y Caducidad.

2. Tratamiento en Legislaciones comparadas.

3. Aplicación de las normas civiles a las limitaciones temporales de responsabilidad bajo un SPA. 


\title{
RESUMEN:
}

El crecimiento económico sostenido que ha experimentado el Perú en las últimas dos décadas ha causado que las operaciones de compraventa de empresas, 0 de M\&A hayan proliferado en nuestro país. El presente artículo busca analizar una figura importante en los contratos de M\&A, las limitaciones temporales a las obligaciones de indemnización, a la luz de las normas civiles que aplican a los contratos de compraventa de acciones según la legislación peruana.

Palabras Clave: Fusiones y Adquisiciones, Contratos de Compraventa de Acciones, Derecho Civil.

\begin{abstract}
:
The sustained economic growth that Peru has experienced during the last two decades has caused the proliferation of acquisitions of companies, or M\&A, in our country. The following article seeks to analyze an important figure in $M \& A$ contracts, the temporary limitations to the indemnification obligations, in light of the civil norms that apply to stock purchase agreements according to Peruvian legislation.
\end{abstract}

Keywords: Mergers and Acquisitions, Stock Purchase Agreements, Civil Law.

\section{INTRODUCCIÓN}

En las últimas dos décadas nuestro país ha experimentado un crecimiento económico sostenido en diversos sectores. Dicho crecimiento no sólo ha traído la expansión de nuestra economía, sino también la sofisticación de los agentes que participan en la misma. En dicho contexto, en el periodo antes indicado hemos visto un incremento, tanto en volumen como en calidad, de operaciones financieras, dentro de las cuales destacan las operaciones de compra y venta de empresas.

En efecto, el crecimiento económico antes mencionado ha causado que las operaciones de compraventa de empresas, o de M\&A —como son conocidas por sus siglas en inglés, Mergers and Acquisitions - hayan proliferado en nuestro país. Como razones subyacentes a dicha proliferación podemos encontrar: (i) la necesidad de las empresas locales de consolidarse - a través de la adquisición de empresas del mismo rubro - para responder a las necesidades de un mercado en expansión; y, (ii) el ingreso de empresas extranjeras en el Perú, toda vez que en la mayoría de casos dicho ingreso se viene dando a través de la adquisición de empresa locales, en vez de a través de la constitución de empresas nuevas.

Quizás determinado por el factor descrito en el literal (ii) del párrafo anterior la proliferación de este tipo de transacciones ha traído consigo que la práctica local, al menos en cuánto a contratos de compraventa de empresas se refiere, se vea fuertemente influenciada por la práctica anglosajona en materia de M\&A. Así, la vasta mayoría de contratos de M\&A en el Perú reflejan la estructura de contratos del mismo tipo en países de tradición anglosajona - principalmente, EEUU—.

En efecto, en el Perú, la adquisición de empresas se instrumentaliza, en la mayoría de casos, a través de contratos de compraventa de acciones -en adelante, "SPA" por sus siglas en inglés, Stock Purchase Agreement - en virtud de los cuales determinado comprador adquiera el íntegro - o una porción-de las acciones representativas del capital social de la empresa target $y$, con ello, adquiera el control de los negocios y operaciones económicas subyacentes.

Tomando en consideración lo anterior, el objetivo del presente artículo será analizar una figura importante en los contratos de M\&A, las limitaciones temporales a las obligaciones de indemnización, a la luz de las normas civiles que aplican a los contratos de compraventa de acciones según la legislación peruana.

\section{LIMITACIONES TEMPORALES PARA INTERPONER RECLAMOS BAJO CONTRATOS DE COMPRAVENTA DE ACCIONES}

Una de los temas más negociados en los SPA son las limitaciones temporales a la responsabilidad del vendedor respecto de las declaraciones y garantías otorgadas en el contrato. 
En efecto, en operaciones de M\&A es usual que el vendedor otorgue diversas declaraciones y garantías. Dichas declaraciones y garantías abarcan diversos aspectos, algunas vinculadas al vendedor mismo - por ejemplo, respecto de su capacidad para celebrar el contrato y/o la obtención de las autorizaciones correspondientes-y otros, muy importantes también, vinculadas a las acciones transferidas y la empresa emisora de dichas acciones.

Así, por ejemplo, es usual que el vendedor otorgue declaraciones y garantías respecto de temas contables, financieros, ambientales, laborales, tributarios, suficiencia de activos, entre muchos otros temas relevantes para el comprador en relación al negocio que está adquiriendo en virtud del SPA.

Como ha sido desarrollado extenso en la literatura relacionada a operaciones de compraventa, la función de dichas declaraciones y garantías es: (i) reducir la asimetría informativa existente entre el comprador y vendedor respecto de la empresa objeto de compraventa y sus negocios; y (ii) asignar riesgos entre las partes en caso se verifique alguna contingencia relacionada con el objeto de las declaraciones y garantías del caso en concreto.

Efectivamente, en relación a lo señalado en el literal (i) anterior, las declaraciones y garantías tienen como finalidad que se reduzca la asimetría informativa existente entre el comprador y vendedor respecto de los negocios de la sociedad target, mediante la revelación por parte del vendedor de determinados aspectos importantes de dicha sociedad vía las declaraciones y garantías del SPA. Dicha revelación complementa la auditoría legal, financiera y comercial que es realizada, al menos en la mayoría de casos, por el comprador.

De otro lado, en relación a lo señalado en el literal (ii) anterior, conviene precisar que en ciertas ocasiones el vendedor no tiene una certeza absoluta respecto del tema materia de la declaración o garantía del caso en concreto. Ello sucede, por ejemplo, cuando las declaraciones están referidas a problemas potenciales que pudiesen derivar en demandas judiciales contra la empresa adquirida por el comprador $\mathrm{y} / \mathrm{o}$ al cumplimiento de normas específicas por dicha empresa. En estos casos, el vendedor puede no tener conocimiento real y efectivo sobre si la empresa en cuestión cumple "en todos los aspectos relevantes con la regulación ambiental", pero emite igualmente la declaración sobre temas ambientales porque en este caso la función de la misma es que el vendedor asuma el riesgo de la materialización de contingencias ambientales originadas en hechos sucedidos con anterioridad a la transferencia de la empresa.

Así las cosas, de verificarse dicha contingencia ambiental en la empresa, el comprador podría reclamar al vendedor por el daño causado por la misma. Usualmente, en estos casos el comprador se encuentra legitimado para solicitar que el vendedor le pague una indemnización, y el reclamo por la misma se encuadrará dentro de las reglas y limitaciones adoptadas por las partes en el SPA.

En suma, las "declaraciones yaseveraciones asignan contractualmente los riesgos inciertos o no conocidos entre las partes, determinando quién deberáasumir las pérdidas futuras que pueda sufrir la empresa. De esta forma, se reducen los altos costos del efecto de la asimetría de la información de los contratantes en la transferencia del control de un negocio"1.

\section{Normas civiles de Prescripción y Caducidad.}

Dentro de las limitaciones antes mencionadas, es usual que las partes pacten restricciones temporales para la presentación de reclamos basados en declaraciones y garantías. Así, por ejemplo, es usual que se pacte que, salvo determinadas excepciones, el comprador renuncie a

1. BOISSET TIZÓN, Rafael. "Las declaraciones y aseveraciones en la compraventa de acciones". En: "Fusiones y Adquisiciones". Lima: 2015, Instituto Peruano de Arbitraje, p. 146. 
plantear reclamos al vendedor por la falsedad o incorrección de las declaraciones y garantías del SPA, luego de transcurrido un plazo determinado desde la fecha de transferencia de las acciones — por ejemplo: 2 años desde la fecha de cierre de la operación de M\&A-.

En tal supuesto, conviene analizar si dichas limitaciones temporales - las cuales están presentes en la inmensa mayoría de contratos de compraventa de acciones-entran en conflicto con las normas civiles relacionadas a prescripción y caducidad, en especial con los artículos 1990, 2000 y 2004 del Código Civil, los cuales señalan lo siguiente:

"Artículo 1990 del Código Civil: El derecho de prescribir es irrenunciable. Es nulo todo pacto destinado a impedir los efectos de la prescripción".

"Artículo 2000 del Código Civil: Sólo la ley puede fijar los plazos de prescripción".

"Artículo 2004 del Código Civil: Los plazos de caducidad los fija la ley, sin admitir pacto en contrario" (subrayado agregado).

Como es conocido, nuestro Código Civil establece que "la prescripción extingue la acción, pero no el derecho mismo" y que "la caducidad extingue el derecho y la acción correspondiente" ${ }^{\prime \prime}$.

Se puede apreciar que ambas instituciones - prescripción y caducidad - extinguen la acción, la cual entendemos como la potestad de acudir a los órganos jurisdiccionales para pedir tutela jurisdiccional efectiva respecto de una pretensión o derecho material que nos asiste. Así, el titular de la pretensión material puede -empleando el derecho de acción-convertir dicha pretensión material en pretensión procesal, entendida esta último como el acto en cuya virtud se reclama ante los tribunales ordinarios o arbitrales la resolución de un conflicto de interés suscitado entre dos partes ${ }^{4}$.

Por su parte, la caducidad - a diferencia de la prescripción- extingue también la pretensión o derecho material que subyace a la acción. Asimismo, otras diferencias importantes entre la caducidad y la prescripción son (i) que los plazos de caducidad no admiten interrupción ni suspensión —salvo por la imposibilidad de plantear la acción ante tribunales peruanos-; y (ii) que la caducidad puede ser invocada también de oficio por el juez -la prescripción sólo puede ser invocada de parte-.

Es importante señalar que el sustento de las normas descritas en el presente trabajo es el interés público. En efecto, tal y como señala Marcial Rubio:

"(...) desde el Derecho Romano se ha considerado que la existencia de la prescripción obedece a razones de interés público. Es decir, para que las relaciones jurídicas en la sociedad adquieran un margen razonable de seguridad hay que establecer plazos dentro de los cuales se pueda ejercitar válidamente las acciones. Transcurridos estos plazos, las relaciones jurídicas se modifican en lo que atañe al respaldo coactivo del aparato de poder -Estado en términos contemporáneos-yentonces, cumplido el plazo prescriptorio, el interesado, y los que se relacionan con él, podrán realizar sus actos en la seguridad que, quien antes tuvo un derecho, ya no puede reclamarlo activamente con éxito mediante la acción ante los tribunales, porque podrá interponerse la excepción de prescripción del caso"s.

2. Artículo 1989 del Código Civil.

3. Artículo 2003 del Código Civil.

4. CASTILLO FREYRE, Mario y MOLINA AGUÍ, Giannina. "¿Qué es lo que extingue la prescripción? Reflexiones acerca del artículo 1989 del Código Civil Peruano". Lima: 2008, pp. 6-7.

5. RUBIO CORREA, Marcial. "Prescripción y Caducidad. La extinción de acciones y derechos en el Código Civil". En: Biblioteca Para Leer el Código Civil. Vol. VII. Lima: Fondo Editorial de la Pontificia Universidad Católica del Perú, 1989. p. 31. 
Asimismo, Rubio señala:

"(...) por conveniencia global de la vida social en general, entonces se establece que el derecho de prescribir es irrenunciable, y que resulta nulo todo pacto destinado a impedir los efectos de la prescripción - artículo 1990- El interés en que las acciones prescriban no es individual sino público, y una de las pruebas más contundentes de ello es que, según el artículo 2000, 'Sólo la ley puede fijar los plazos de prescripción.' En otras palabras, que una acción no prescriba no corresponde al interés individual del beneficiario, sino al interés público encarnado en la normalización de las relaciones jurídicas".

Sin perjuicio de lo antes mencionado, debemos señalar que el interés del beneficiario del plazo prescriptorio es siempre definitivo, pues es dicha persona quien tiene la última palabra respecto de la aplicación efectiva —o no aplicación efectiva- del instituto de la prescripción. En efecto, no sólo la prescripción ya ganada puede ser materia de renuncia, sino que el beneficiario de la prescripción puede interrumpir su decurso, a través del reconocimiento de la obligación.

Las características descritas en el párrafo anterior constituyen, como ya hemos mencionado, diferencias muy importantes entre la prescripción y la caducidad. En efecto, la caducidad no admite suspensión ni interrupción —salvo por la imposibilidad de reclamar ante tribunales peruanos-; del mismo, la caducidad sí puede ser invocada de oficio por un juez, al margen de la voluntad del beneficiario de la misma.

Adicionalmente, consideramos pertinente señalar una diferencia adicional entre las instituciones civiles bajo comentario. A nuestro parecer, las partes si pueden pactar plazos de caducidad, siempre que no contravengan un plazo ya previamente fijado por ley para el supuesto de hecho que se quiere regular contractualmente. Efectivamente, en tanto los plazos de caducidad son de orden público, todo pacto que busque modificar convencionalmente un plazo de caducidad que ya está fijado en la ley debe ser nulo en aplicación del artículo $\mathrm{V}$ del Título Preliminar del Código Civil. Ello en virtud a una interpretación sistemática de los artículos 1990 y 2004 del Código Civil.

En esa misma línea, y diferencia de la caducidad, consideramos que los plazos de prescripción no pueden tener origen convencional, toda vez que nuestro código civil establece que "Sólo la ley puede fijar los plazos de prescripción" (subrayado agregado), lo cual constituya una marcada y relevante diferencia en relación con la caducidad, puesto que el artículo en referencia excluye expresamente que se fijen plazos de prescripción por fuentes distintas a norma con rango de ley.

\section{Tratamiento en Legislaciones comparadas.}

En relación a este tema, la legislación comparada ofrece soluciones similares a las otorgadas por nuestro Código Civil. Así, por ejemplo, bajo la ley de Delaware, las partes de un contrato pueden reducir el plazo de prescripción aplicable, puesto que ello es consistente con la ratio legis detrás de la institución de la prescripción bajo dicha jurisdicción. Por el contrario, un pacto destinado a extender la vigencia de determinadas declaraciones y garantías por encima del plazo de prescripción aplicable - por ejemplo, cuando se pacta que las declaraciones y garantías sobrevivirán "indefinidamente" - no sería admisible bajo la legislación de Delaware ${ }^{7}$.

En la misma línea, Klaman y Felger señalan que el pacto por el cual se establece que las declaraciones y garantías se mantendrán vigentes de

6. Ibíd., p. 32.

7. HERING, Louis G. y DIVICENZO, Melissa A. "Considerations for Contractual Provisions Extending Statutes of Limitations". Disponible en: <https://businesslawtoday.org/2014/05/considerations-for-contractual-provisionsextending-statutes-of-limitations/>. 
manera indefinida no es válido, y que en tal caso aplicará el plazo de prescripción regular según la naturaleza del asunto. Ello en atención a las políticas públicas detrás de los plazos de prescripción y a la negativa de las cortes de extender el plazo de prescripción contractual por un período más largo que el fijado legislativamente ${ }^{8}$.

En ese sentido, podemos apreciar que bajo la legislación de Delaware, las limitaciones temporales respecto de la vigencia de las declaraciones y garantías son permitidas en tanto establezcan un período menor al señalado por la ley para el caso en concreto; contrariamente, si dicho plazo contractual es mayor que el fijado por ley, el pacto se convierte en inválido y es el plazo legal el que resulta de aplicación.

\section{Aplicación de las normas civiles a las limitaciones temporales de responsabilidad bajo un SPA.}

De acuerdo con lo anterior, conviene analizar si las limitaciones temporales que se incluyen usualmente en los SPA colisionan con las normas de prescripción y caducidad de nuestro ordenamiento civil; específicamente, con aquellas que establecen que no se pueden renunciar a prescripciones no ganadas, y aquellas que establecen que los plazos de prescripción y caducidad se fijan por ley.

El tema es bastante discutible y, lamentablemente, no hay mayor desarrollo jurisprudencial ni a nivel arbitral - a nuestro conocimientosobre este tema. Sin embargo, y manteniendo una posición conservadora sobre el tema, somos de la opinión que las limitaciones temporales incluidas usualmente en los SPA respecto de la responsabilidad de los vendedores - ya sea vía la inclusión de un plazo específico durante el cual ciertas declaraciones y garantías se mantienen vigentes, o vía la inclusión de un plazo general de responsabilidad del vende- dor- podrían ser interpretadas por nuestros operadores legales - jueces - como plazos de prescripción y/o caducidad establecidos de manera convencional $y$, por tanto, podrían colisionar con las normas civiles descritas en los párrafos anteriores.

Así, por ejemplo, es usual que en los contratos de compraventa de empresas el vendedor declare que es el único propietario de las acciones materia de compraventa, y que no existen derechos de terceros sobre las mismas. Adicionalmente, es bastante usual que se pacte que dichas acciones están libres de cargas, gravámenes y/o cualquier otro tipo de pacto que restrinja su uso y plena disposición, salvo por aquellos expresamente informados al comprador. Asimismo, es usual que se convenga que dichas declaraciones y garantías del vendedor se mantengan vigentes por plazos bastante extensos - por ejemplo, de manera indefinida, o por diez años desde la celebración y cierre de la transacción de M\&A del caso en concreto-.

Sobre lo anterior, es importante analizar qué sucedería si dichas declaraciones y garantías resultan falsas $y$, como consecuencia de ello (i) el comprador es despojado de las acciones por que un tercero tenía derecho a las mismas; o (ii) el comprador adquiera las acciones sujetas a un gravamen - por ejemplo, usufructo o convenio de cesión de algunos derechos políticos-.

En el primer caso, bien podría argumentarse que el supuesto de hecho calza dentro de las obligaciones de saneamiento, específicamente, con el saneamiento por evicción, en cuyo caso resultaría de aplicación un plazo de caducidad de un año desde que el comprador es despojado de la propiedad o posesión de las acciones. En efecto, nuestro Código Civil establece:

"Artículo 1484 del Código Civil: Hay lugar a saneamiento en los contratos relativos a la

8. KLAYMAN, Barry M. y FELGER, Mark. "The interpretation of Contractual Survival Clauses". Disponible en: <http:// portal/SiteAssets/Lists/Announcements/EditForm/2014-03-12\%20DBCl,\%20The\%20Interpretation of Contractual Survival Clauses.pdf $>$. 
transferencia de la propiedad, la posesión o el uso de un bien".

"Artículo 1485 del Código Civil: En virtud del saneamiento el transferente está obligado a responder frente al adquirente por la evicción (...)".

"Artículo 1491 del Código Civil: Se debe el saneamiento por evicción cuando el adquirente es privado total o parcialmente del derecho a la propiedad, uso o posesión de un bien en virtud de resolución judicial o administrativa firme y por razón de un derecho de tercero, anterior a la transferencia".

"Artículo 1500 del Código Civil: El adquirente pierde el derecho a exigir el saneamiento:(...) 5. Por caducidad, siendo el plazo de esta de un año a partir de la fecha en que se produjo la evicción".

Así, por ejemplo, si el comprador es despojado de la propiedad de las acciones a los tres meses de efectuada la transferencia de las mismas, y si por cualquier razón dicho comprador demanda al vendedor una vez transcurrido un año desde efectuado el despojo, creemos que es probable que el vendedor tenga éxito si plantea una defensa basada en la caducidad del derecho a solicitar la evicción, aún cuando el comprador argumente que su acción está sustentada en la falsedad de una declaración y garantía del contrato y que, por tanto, se encuentra dentro del plazo fijado por ambas partes para dicho tipo de reclamos.

Del mismo modo, creemos que un vendedor podría defenserse con éxito ante un reclamo del comprador por la existencia de gravámenes sobre las acciones que fuese planteado fuera del plazo de caducidad establecido para reclamar el saneamiento por vicios ocultos ${ }^{9}$. Ello asumiendo que no ha habido pactos en el SPA específicos por los cuales el comprador renuncia expresamente al saneamiento.

No creemos que las normas civiles comentadas hayan sido diseñadas para este tipo de operaciones financieras. Creemos que estas normas han sido pensadas para transacciones de compraventa más tradicionales, y que no serán de fácil aplicación por los operadores legales que tengan que encontrarse con este tipo de controversias.

Si bien somos conscientes que el tema es controvertido y complejo, creemos que lo señalado en el presente artículo puede servir de base para la discusión teórica, toda vez que somos conscientes que la proliferación de operaciones de M\&A en el Perú llevará consigo, más temprano que tarde, que este tipo de discusiones teóricas sean testeadas en tribunales judiciales y arbitrales peruanos.

9. Para tales casos, nuestro Código Civil establece un plazo de caducidad de tres meses desde la fecha de recepción del bien mueble - acciones-. 